\title{
AS LEIS HISTÓRICAS DA POPULAÇÃO: MARCO TEÓRICO PARA A COMPREENSÃO DA REPRODUÇÃO HUMANA
}

Rosa Maria Godoy Serpa da Fonseca*

\begin{abstract}
A partir do conceito de população, e feita a exposição das leis históricas que regem o desenvolvimento demográfico, como expressão das formas peculiares de organização das diferentes sociedades humanas no decorrer da história.
\end{abstract}

UNITERMOS: demografia, reprodução humana, controle da natalidade

As transformações sociais ocorridas no decurso da história da humanidade podem ser explicadas de várias maneiras, inclusive por leis que se constituem em generalizações teóricas que regem o próprio desenvolvimento da sociedade. No caso dos fenômenos demográficos são chamadas de "leis históricas da população" e o fato de serem inerentes a cada modo de produção específico referenda o seu caráter eminentemente histórico. (VALENTEl, 1987)

É óbvio que no produto final "população ou constituição populacional" estas leis são coadjuvadas por vários outros fenômenos, no entanto, a sua compreensão pode elucidar inúmeros equívocos e desnaturalizar o processo demográfico, historicizando-o.

Desta forma, população refere-se a um conjunto de indivíduos que realizam a sua atividade vital no quadro de uma determinada sociedade, vivendo num território delimitado e constituindo a base natural e, ao mesmo tempo, social de uma dada coletividade. Assim, a população não é constituída por um conjunto aleatório de indivíduos, mas um conjunto determinado pelas condições materiais concretas de reprodução social da coletividade. Reproduz, ao mesmo tempo, a estrutura social desta coletividade, como por exemplo, as classes sociais nas sociedades classistas. Sem tal embasamento concreto, este conceito resulta numa mera abstração estéril, sem fundamento científico, no dizer de MARX e ENGELS. (MARX, 1985; SANTOS, 1990)

*Professor Doutor. Docente do Departamento de Enfermagem em Saúde Coletiva da Escola de Enfermagem da Universidade de São Paulo 
As condições nas quais o homem se reproduz dependem diretamente da estrutura das diversas formas de organização social e, por isto, as leis da população devem ser estudadas, tendo-se em conta a concretude de uma dada formação social e não de uma "forma abstrata", que não considera as formas historicamente diferentes da estrutura social. (LENIN apud $V$ ALENTEI, 1987)

Desta forma, os processos demográficos constituem a base natural do desenvolvimento da população e são determinados pelo estágio de desenvolvimento em que se encontram as forças produtivas e as relações de produção de cada sociedade. Dado que esses processos são eminentemente sociais na sua natureza, isto leva a que não se tenha, numa dada formação social concreta, nenhuma forma "pura" de comportamento demográfico, uma vez que coexistem na mesma, diversos modos de produção. Com a predominância de um deles, verifica-se a hegemonia dos comportamentos demográficos que the são peculiares, sem que, no entanto, possa ser negada a existência de formas mescladas de processos populacionais.

Deve-se entender que qualquer explicação para a constituição de um espaço social não deve subjugar-se apenas a uma visão economicista da dinâmica populacional, mas considerar que a experiência humana inclui a própria formação da cultura, que nela interfere fundamentalmente.

Por cultura compreende-se "o conjunto dos produtos das representações e dos procedimentos postos pelos homens enquanto seres sociais. Tudo aquilo que não e posto como mero resultado da ação mecânica da natureza, tudo aquilo que passa por uma impregnação de algum tipo de intervenção humana. Dai significar também o processo global dinâmico pelo qual esses elementos que a constituem se inter-relacionam e são apropriados, pelas vias da educação e das demais formas de comunicação, pelos indivíduos que compõem a sociedade. Num plano ainda mais abrangente, a cultura significa essa dimensão mais espiritual da vida social ou individual e que é constituída por processos subjetivos de simbolização, de imaginação e de sensibilidade". (SEVERINO, 1993)

Por esta razão e que não se pode esperar que qualquer mudança populacional ocorra imediatamente subseqüente às transformações estruturais. Ao contrário, as transformações na estrutura populacional se dão paulatinamente, à medida que se absolutiza o modo de produção dominante. Isto ocorre, especialmente, sob a influência dos processos superestruturais que se seguem às mudanças na base econômica em relação dialética com os processos individuais subjetivos. Como em todos os processos sociais, isto não se dá linearmente, mas segundo as leis de desenvolvimento dialético. (FONSECA, 1990)

Neste ensaio, ater-me-ei a análise dos processos históricos que ocorrem na população subseqüentes as mudanças estruturais e superestruturais de cada modo de produção, não levando em conta outros fenômenos que igualmente interferem nas mudanças populacionais como a condição social da mulher, por exemplo. Este tema deverão ser abordado num outro ensaio posterior.

$\mathrm{Na}$ história do desenvolvimento social das sociedades ocidentais, podemos 
detectar as leis específicas que regem os processos demográficos, nos vários modos de produção. No período mais primitivo da história, quando o ser humano se diferenciou do mundo animal através do trabalho, os determinantes dos ritmos de reprodução da população eram as leis biológicas, com grande influência do processo de seleção natural que reservava major possibilidade de sobrevivência para os indivíduos mais capazes de enfrentar os fenômenos da natureza. A vida dos humanos primitivos era fundamentalmente voltada para a sobrevivência, em condições de vida altamente desfavoráveis em vista das adversidades da fome, do frio e da convivência conflituosa dos seres humanos entre si e com os animais.

À vista disto, há razões para se estimar para esse período, altas taxas de mortalidade, especialmente infantil, que, em algumas regiões, chegaram a ser de $45 \%$, só não dizimando a espécie humana, em virtude das altas taxas de natalidade vigentes. A despeito das mulheres passarem a maior parte do seu período de fertilidade procriando, não se pode falar em acentuado crescimento populacional nessa época, porque a idade média não era superior a 20 ou 30 anos. Ainda assim, quando os agrupamentos humanos atingiam tamanhos incompatíveis com a quantidade de alimento disponível ou com a possibilidade de se locomoverem para regiões com condições mais favoráveis de sobrevivência, era constante a pratica de medidas reguladoras do tamanho das populações. Tais medidas incluíam o aborto, o infanticídio e o abandono dos mais idosos e dos incapazes fisicamente. (TANNAHILL, 1987)

O domínio do fogo e a passagem para a agricultura e a pecuária foram etapas importantes no desenvolvimento das forças produtivas das sociedades primitivas. Quando estas iniciaram o processo de domínio das forças naturais, seguiu-se a este um aumento populacional considerável, especialmente pela melhoria das condições nutricionais, evitando a extinção da raça humana e levando a transformações importantes no desenvolvimento das forças produtivas rumo as transformações nas relações de produção. A lei determinante da população das formações primitivas, no entanto, continuou sendo a luta continua e coletiva pela sobrevivência do grupo.

Nesse período têm início também o processo migratório acentuado e o comércio, no processo de interação das várias comunidades humanas existentes. Isto influenciou sobremaneira o comportamento reprodutivo e mesmo a própria constituição biológica da raça humana. A este respeito, cita TANNAHILL:

"O que a migração e o comércio fizeram pelos povos da era neolítica foi estimular um tipo de procriação mesclada, algo inteiramente novo na história do mundo. Pelo final do período, a diversidade genética resultante, aliada a uma nutrição superior e a nova autosegurança da humanidade, produziu uma população que era, não apenas muito maior em número, como também de qualidade mais dinâmica". (TANNAHILL, 1987)

A desagregação do sistema tribal conduziu ao aparecimento da sociedade de classes. Esta surgiu em diferentes períodos, no entanto, sob a forma de escravatura em quase todas as em quase todas as formações sociais, se bem que com peso diferente nas diversas 
regiões, pois se em alguns lugares os escravos constituíam a força produtiva básica, em outros, eram minoria.

Isto, entretanto, não fez com que as leis de população se configurassem muito diferentemente de um lugar para outro. Ao contrario, o que se observa e que estas leis perderam gradativamente o caráter genérico que Ihes era peculiar na sociedade primitiva e foram se diferenciando por classes sociais a medida que estas iam se estruturando.

De uma maneira geral, isto ocorreu da seguinte forma: aos escravocratas não interessava a reprodução descontrolada da classe escrava, pois os gastos com a renovação da força de trabalho, desta forma, poderiam ser maiores do que com a aquisição de um novo escravo adulto, no mercado. Por esta razão, havia um controle populacional intenso dessa classe através de medidas que iam desde a proibição de relacionamentos sexuais entre escravos, até aborto e infanticídio obrigatórios. A natalidade baixa era acompanhada de alta mortalidade pelas condições extremamente precárias de vida e trabalho dessa população, cuja reposição só era garantida através da escravização de populações livres que se seguiam às conquistas militares.

Por outro lado, a população juridicamente livre, não escrava, continuou durante muito tempo com as mesmas características reprodutivas da população primitiva, ainda que um pouco facilitada pelo crescente processo de dominação das forças naturais através da aquisição e difusão do conhecimento sobre as técnicas reguladoras da pecuária e da agricultura. A despeito disto, continuavam ainda altas as taxas de mortalidade pelas doenças ou pelas guerras, acompanhadas da alta natalidade compensatória, reforçada pelos princípios religiosos nascentes que privilegiavam os rituais de fecundidade, voltados para a manutenção das tradições primitivas (GREER, 1987).

Apesar disto e consoante os processos de dominação da natureza, verifica-se, nesse período, o uso de praticas reguladoras da fecundidade, tais como: uso de métodos anticoncepcionais, principalmente vinculadas a relacionamentos amorosos ilícitos para a época; o incremento do celibato; a limitação dos casamentos e a criação de grandes exércitos regulares com a conseqüente separação da família, entre outras.

Estas práticas ou mantiveram-se tais práticas num nível baixo o suficiente para alterar muito pouco os padrões de fertilidade correntes ou, quando os índices de natalidade caíram o suficiente para ameaçar a soberania do Estado emergente, foram formuladas e implementadas políticas voltadas para o incremento da natalidade. A duração da vida media continuava baixa e o ritmo de crescimento populacional muito desigual nas diversas formações sociais, intimamente relacionado a ocorrência de guerras ou epidemias que agora tinham maior possibilidade de se alastrar, seja pelo crescente desejo de poder do homem sobre seus semelhantes, seja pelo processo de urbanização que começava a se consolidar (VALENTEI, 1987).

A sociedade feudal se caracterizou pela propriedade da terra, que era o principal meio de produção existente, pela classe feudal. Isto pressupunha relações de produção de exploração do trabalho servo que constituía a principal força produtiva. Os servos, assim como os escravos, eram propriedade do senhor feudal, só que, diferentemente daqueles, 
apesar de poderem ser vendidos, não podiam ser mortos pela vontade do dono. Essa mudança nas relações de produção, em relação à sociedade escravagista, fez com que fosse valorizada a reprodução biológica dos servos, pois, além do poder do feudo estar diretamente relacionado à quantidade de terras e servos que continha, a reprodução e manutenção da força de trabalho era de responsabilidade da família e não diretamente do senhor, como na escravatura.

Além do trabalho voltado a produção e reprodução da riqueza do feudo, o servo tinha que dedicar-se ao sustento da sua família que também trabalhava no cultivo da terra, constituindo mão de obra suplementar. A alta natalidade, nessa época, era garantida por mecanismos estimuladores da fertilidade, como por exemplo, o estímulo aos casamentos precoces, imediatamente subseqüentes à menarca; a estabilidade conjugal e a proibição do uso de medidas anticonceptivas, aborto e infanticídio.

A Igreja Católica Apostólica Romana, principal instituição européia da Idade Média, regulava e controlava todas essas normas, imputando sérias medidas repressivas aos que insistiam em desobedecê-las. A despeito dessa proibição, há registro histórico do uso destas práticas na sociedade européia durante todo o período feudal, embora em magnitude insuficiente para alterar significativamente os padrões reprodutivos vigentes. (TANNAHILL, 1987; GREER, 1987)

A mortalidade continuava alta, devido às mesmas causas verificadas no período anterior, agravada pelo grau dos conhecimentos científicos e pela repressão que obstaculizava a cura e o controle das doenças epidêmicas. Nas sociedades não européias, o feudalismo ou os modos de produção que se the assemelhavam, manifestaram-se com contornos qualitativamente diferenciados, no entanto, valorizando as mesmas características reprodutivas.

Em resumo, eram próprias das sociedades pré-capitalistas duas particularidades fundamentais da reprodução populacional:

1. as altas taxas de natalidade condicionadas pelos casamentos precoces, pela ausência de meios preventivos da gravidez e pela difusão geral das tradições de fecundidade;

2. as altas taxas de mortalidade condicionadas pelo baixo desenvolvimento das forças produtivas (entre elas, a ciência) e pelas condições de vida extremamente difíceis como a fome, as doenças e as guerras (VALENTEI, 1987).

Nesta época, já predominavam os processos demográficos diferenciados segundo os grupos sociais existentes, sendo valorizados socialmente aqueles comportamentos reprodutivos controladores do tamanho daqueles que ocupavam uma posição de subalternidade social, implementando-se o seu desenvolvimento de acordo com os interesses dominantes.

Outro fato a considerar nos processos demográficos são os movimentos migratórios, ocorridos quando o superpovoamento das regiões levava a uma pressão suficientemente grande sobre o excedente populacional, no sentido da ampliação das fronteiras, gerando guerras como resultado de conflitos inevitáveis. Surgiram, assim, as primeiras colônias nos diversos continentes. 
A superação das relações de produção feudal resultaram modo capitalista de produção. A essência da lei capitalista da população e que a acumulação do capital conduz, obrigatoriamente, a que haja sempre uma parte da população operária excedente, afastada da produção e, por esta razão, condenada a condições bastante precárias de existência. E o chamado "exército industrial de reserva" cuja existência, em quantidade controlável, garante as condições de exploração do operariado pelas classes dominantes, através da regulação dos salários.

Esta lei é também chamada de "lei do superpovoamento relativo" e VALENTEI se refere a ela e aos seus efeitos sociais, na seguinte citação:

"Na sociedade burguesa, a aparição e o aumento do contingente do exército de trabalho de reserva, ou seja, dos desempregados, e uma lei econômica da população própria do modo capitalista de produção. Esta lei reflete a situação real do assalariado nesta sociedade, onde ele e um apêndice do capital, onde ele pertence ao capital, tanto quando produz, como quando não produz, por que mesmo quando o operário está ocupado na satisfação das suas necessidades individuais, reproduz da mesma maneira a sua capacidade de trabalho, de que o capitalista pode ter necessidade. Um operário contribui durante toda a sua vida ativa para a acumulação do capital". (BOTTOMORE; HIMMELWEIT, 1988)**

Por esta razão, a lógica capitalista está voltada para o controle da reprodução da força de trabalho das classes trabalhadoras, ou seja, sob esta ótica, essas classes sociais necessitam ser mantidas dentro de limites que não atentem contra a manutenção do sistema, sendo estimuladas a se reproduzir quando há falta de mão de obra e, ao contrário, estimuladas à contenção da reprodução biológica, quando a quantidade de mão de obra se torna suficiente ou excessiva, frente aos objetivos do capital.

Para entender esta lei, e necessário compreender que o desenvolvimento do modo capitalista de produção determinou o caráter específico dos seus processos demográficos, de acordo com as fases que atravessou até nossos dias. Assim, a passagem do feudalismo para o capitalismo foi acompanhada de um desenvolvimento intenso das forças produtivas que não podia prescindir de um rápido crescimento populacional, para atender as exigências do capital em expansão.

$\mathrm{Na}$ época inicial do capitalismo, na época da livre iniciativa, o crescimento populacional foi acelerado, tanto pelo aumento das taxas de natalidade, quanto pelo início do processo migratório dos campos às cidades, para atender à demanda de mão-de-obra da industrialização incipiente.

\footnotetext{
**Para aprofundar na lei capitalista de população ver: BOTTOMORE, T.; HIMMEL WEIT, S População. In: BOTTOMORE, 1988 e SHAIKH, A Exército industrial de reserva. In: BOTTOMORE, 1988
} 
No entanto, os últimos anos do século passado e primeiros deste registraram uma queda da natalidade nos países onde o processo capitalista avançou mais rapidamente, em especial, em pauperização das classes trabalhadoras, pela agudização das contradições a esse sistema produtivo. Esgotadas as possibilidade de expansão pela falta de mão-de-obra de baixo custo dentro de suas próprias fronteiras, tornou-se necessária à ampliação dos horizontes da produção, a busca de força de trabalho externa, em condições favoráveis de exploração.

Seguiram-se a este processo as duas grandes mundiais, como necessidade da expansão política e econômica dos países mais adiantados, na luta entre si, pelo domínio dos povos menos favorecidos economicamente.

No pós-guerra imediato, verificou-se um aumento compensatório da natalidade que, em seguida, voltou a cair, alterando a composição populacional destes países. Este descenso da natalidade foi acompanhado por um grande avanço tecnológico, responsável pelo controle das doenças que, durante séculos, dizimavam grandes massas humanas, de forma que não houve, nos primeiros tempos, uma grande redução populacional.

Com o passar do tempo, entretanto, as taxas de mortalidade estabilizaram-se, fazendo com que fosse mais agudamente sentida a queda da natalidade. Diante deste processo, que reduziu significativamente a oferta de mão-de-obra, o capitalismo, pra se expandir, precisou romper as fronteiras regionais para se internacionalizar. Isto aconteceu, dividindo os países em dois grandes blocos: o bloco central, mais adiantado economicamente, detendo a propriedade do capital e dos meios de produção, entre eles o controle tecnológico da produção, e o periférico, mais atrasado, potencialmente um grande fornecedor de força de trabalho ao bloco central, especialmente pelos altos índices de reprodução existentes, remanescentes do modo de produção feudal ainda evidente nesses territórios.

Mantendo a mesma lógica de exploração existente na sociedade de classes, estes dois blocos passaram a interagir dialeticamente sob a égide de um modo de produção privilegiando características diferenciadas de reprodução biológica, segundo a função social dos diferentes contingentes populacionais. Nesta época, interessava ao bloco central o estímulo à procriação e à migração nos países periféricos, para preencher as lacunas de mão-de-obra requisitada pela industrialização ascendente.

A lei capitalista da população estimula então a constituição, nesses países, de um exército de reserva suficiente para a manutenção das exigências do numérico das classes trabalhadoras. Nos países centrais, desde o início do século, verificavam-se movimentos que visavam a contenção dos nascimentos.

Em nível mundial, o controle da reprodução humana surgiu nas Estados Unidos no início desde século, em decorrência das transformações pelas quais passava a sociedade norte-americana na época, advindas da industrialização e da urbanização e que haviam determinado transformações no papel da mulher e da família. Surgida num primeiro instante, como uma estratégia para a redefinição do papel da mulher na sociedade, contestando 
posições conservadoras que Ihe atribuíam um lugar eminentemente doméstico restrito aos afazeres do lar e ao cuidado dos filhos, aos poucos, foi sendo transformado em argumento de controle social das classes dominadas, a partir da constatação de que uma quantidade não controlada de pessoas destas classes, colocaria em risco toda a condição de dominação vigente. (OLIVEIRA, 1988)

Este processo revelou que o desenvolvimento das forças produtivas exige uma redução numérica do exército industrial de reserva, pois o aumento da produtividade reduz quantitativamente a necessidade da força de trabalho humana, ao mesmo tempo em que exige dela maior qualidade. Assim, o que passou a ser exigido pelo sistema econômico, a partir desse estágio de desenvolvimento das forças produtivas, tanto no que toca ao avanço tecnológico na industrialização, como na organização dos trabalhadores na defesa dos seus interesses de classe, é a redução e não mais o crescimento das classes trabalhadoras.

Para as classes dominantes, o tamanho descontrolado das classes trabalhadoras constitui uma ameaça, pois, no confronto da luta de classes, pode ser desestabilizada a ordem social vigente, colocando em perigo a hegemonia das primeiras, numericamente inferiores.

A partir do momento em que os países periféricos conseguiram constituir um exército de reserva suficiente para a manutenção das condições capitalistas de exploração, tornou-se necessária a mudança da sua estrutura populacional com a redução numérica das classes trabalhadoras, a semelhança do processo ante ocorrido nos países centrais. Ocorre que nestes, o processo seguiu o curso esperado das transformações sociais e nos demais teve que ser implantado, embora sub-repticiamente, porque o longo tempo demandado para mudanças estruturais colocaria em risco a lógica do sistema.

Indubitavelmente, concomitante à redução populacional dos explorados, aconteceria o desenvolvimento da sua consciência social de classe na direção da exigência de melhores condições de vida e trabalho, contrárias à situação de exploração vigente. Assim, as políticas públicas, de francamente pró-natalistas passaram a controlistas, buscando seus pressupostos em teses burguesas, desenvolvidas anteriormente nos países centrais, sobre a incompatibilidade entre o desenvolvimento econômico e o crescimento populacional.

A principal teoria neste sentido foi desenvolvida, no final do século passado, pelo pastor anglicano Thomas Malthus, na Inglaterra. Segundo esta, há uma desproporção entre a possibilidade da produção de alimentos e o crescimento populacional e só a redução deste permitiria a compatibilidade entre as necessidades e os recursos alimentares, potencialmente disponíveis para toda a humanidade. (ROUMIE, 1986)

Baseados nestes fundamentos matemáticos, os neomalthusianos passaram a advogar a tese da pobreza gerada pelo subdesenvolvimento econômico e, em nome da sua superação, propor medidas reducionistas. Esta tese, com a ampla aceitação das classes 
dominantes, passou a fundamentar as políticas públicas de saúde e educacionais e, através da propagação dos seus pretensos benefícios pelas diversas formas de manifestação da consciência social, acabou sendo amplamente aceita pela sociedade como um todo. Passou a não importar muito a forma pela qual os objetivos são alcançados e as soluções para os problemas sociais jamais são vinculadas a transformações estruturais profundas na forma de organização social. (OLIVEIRA, 1988)

O que se constata, daquele momento histórico em diante, é uma outra forma de manifestação da mesma lei de superpovoamento relativo do capitalismo, agora privilegiando o controle e não mais a expansão do exército industrial de reserva.

No entanto, este controle não pode ser muito rigoroso, pois um outro aspecto importante também deve ser considerado para a expansão do sistema capitalista, ou seja, o relativo não só a produção, mas ao consumo da riqueza produzida.

A população é considerada como a principal força produtora e, ao mesmo tempo, consumidora da sociedade. Para Marx, a produção e o consumo são pólos da mesma contradição, intimamente ligados um ao outro, um condicionando a existência do outro. Em um determinado trecho do texto "Para a crítica da economia política" o autor frisa que a produção é imediatamente consumo e este, imediatamente produção. (MARX, 1985)

Além disso, existem dois tipos de consumo: o primeiro chamado de consumo produtivo, referente ao consumo que é feito durante o ato de produção, através do qual o trabalhador libera energia necessária para o trabalho e o segundo, chamado de consumo propriamente dito, concebido como "antítese destrutora da produção", referente ao consumo de outros bens produzidos, não diretamente relacionados ao ato de produzir.

Assim sendo, o consumo produz, de uma dupla maneira, a produção: em primeiro lugar porque o produto não se toma efetivo senão no consumo e, em segundo, porque o consumo cria a necessidade de uma nova produção. A este respeito, cita:

“... o consumo cria a necessidade de uma nova produção, ou seja, o fundamento ideal, que e move internamente a produção, e que é a sua pressuposição. O consumo cria o impulso da produção; cria também o objeto que atua na produção como determinante da finalidade. Se é claro que a produção oferece o objeto de consumo na sua forma exterior, não é menos claro que o consumo põe idealmente o objeto da produção, como imagem interior, como necessidade, como impulso e como fim. O consumo cria os objetos da produção de uma forma ainda mais subjetiva. Sem necessidade não há produção, mas o consumo reproduz a necessidade". (MARX, 1985)

Assim sendo, a lógica do capitalismo é a de que sem consumo não há a 
possibilidade do aumento da produção, da extração do lucro e conseqüentemente da reprodução do capital. O capitalismo necessita que a população exerça cada vez mais o seu papel de consumidora dos bens produzidos, para gerar a necessidade da produção de outros bens. Por isto, não pode prescindir de todas as classes sociais, especialmente das classes trabalhadoras, até porque, em tamanho, são muito maiores que a burguesia, portanto, maiores consumidoras, em potencial.

Assim, estas classes têm socialmente, uma dupla função: produzir e consumir o que foi produzido, mesmo que este consumo seja secundário, em relação às exigências de consumo da burguesia.

A riqueza produzida, se destinada exclusivamente às classes dominantes, está fadada a ser muito pequena, limitando muito as possibilidades de reprodução do capital. Para manter esta situação dentro de limites controláveis, a ideologia burguesa cria e valoriza necessidades que conduzem as classes trabalhadoras à aspiração de perfis de consumo semelhantes aos seus, no entanto, inatingíveis se mantidos os altos níveis de crescimento populacional.

É evidente o reflexo disto no posicionamento da família proletária diante do estímulo ao consumismo desenfreado, privilegiando necessidades que criam a ilusão de ascensão social. Isto, sem dúvida, interfere nos padrões reprodutivos destas classes que vêem na contenção das taxas de natalidade uma alternativa, não só contra a pobreza e a falta de condições materiais de sobrevivência, mas também, como saída para a satisfação das necessidades criadas pela produção.

Diante de tudo isto, pode-se concluir que a reprodução da população, como principal força produtora da sociedade, é um fenômeno eminentemente social que durante a história do desenvolvimento da sociedade se dá, fundamentalmente, de acordo com a forma como a mesma se organiza para a produção da vida social. Este processo segue leis gerais que se particularizam de acordo com a formação social em tela.

\section{HISTORICAL LAWS OF POPULATION: THEORY FOR THE UNDERSTANDING OF HUMAN REPRODUCTION}

Beginning with the concept population, the author develops the historical laws that rule demographic development, which is an expression of the particular forms of organization in different human societies throughout history.

UNITERMS: human reproduction, birth control, demography 


\section{LAS LEYES HISTÓRICAS DE LA POBLACIÓN: MARCO TEÓRICO PARA LA COMPRENSIÓN DE LA REPRODUCCIÓN HUMANA BIOLÓGICA}

A partir del concepto de población, es hecha la exposición de las leyes históricas que rigen el desarrollo demográfico, como expresión de las formas peculiares de organización de las diferentes sociedades humanas en el transcurso de la historia.

UNITERMOS: demografía, reproducción humana, control de la natalidad

\section{REFERÊNCIAS BIBLIOGRÁFICAS}

01. BOtTOMORE, T., HIMMELWEIT, S. População. In: BOTTOMORE, T. Dicionário do pensamento marxista. Rio de Janeiro: Jorge Zahar, 1988. p.453.

02. FONSECA, R.M.G.S. da. Mulher, reprodução biológica e classe social: a compreensão do nexo coesivo através do estudo dialético do perfil reprodutivo biológico de mulheres atendidas nas Unidades Básicas de Saúde. São Paulo, p. 336. Tese (Doutorado) Escola de Enfermagem, Universidade de São Paulo.

03. GREER, G. Sexo e destino: a política da fertilidade humana. Rio de Janeiro: Rocco, 1987. p.476

04. MARX, K. O capital: crítica da economia política. São Paulo: Nova Cultural, 1985.

05. OLIVEIRA, M.A.C. A reprodução humana em uma sociedade de classes: estudo dialético da representação de um conjunto de enfermeiras. São Paulo, p.242. Dissertação (Mestrado) - Escola de Enfermagem, Universidade de São Paulo, 1988

06. ROUMIE, P. Controle da natalidade: a quem interessa. São Paulo: Paulinas, 1986.

07. SANTOS, M. Por uma geografia nova - da crítica da geografia à geografia crítica. São Paulo: HUCITEC, 1990.

08. SEVERINO, A.J. Filosofia. São Paulo: Cortez, 1993.

09. SHAIKH, A. Exército industrial de reserva. In: BOTTOMORE, T. Dicionário do pensamento marxista. Rio de Janeiro: Jorge Zahar, 1988. p. 144.

10.TANNAHILL,R. O sexo na história. São Paulo: Companhia das Letras, 1987.

11. VALENTEI, D. Teoria da população. Moscou: Progresso, 1987. p.321. 